\title{
Color-rendering of Daylight from Water-filled Light Pipes
}

Authors

Ross McCluney, Ph.D.

\author{
Original Publication
}

McCluney, Ross, "Color-rendering of Daylight from Water-filled Light Pipes", Reprinted from Solar Energy Materials 21 (1990) 191-206.

\section{Publication Number}

FSEC-PF-423-90

\section{Copyright}

Copyright (C) Florida Solar Energy Center/University of Central Florida 1679 Clearlake Road, Cocoa, Florida 32922, USA

(321) 638-1000

All rights reserved.

\section{Disclaimer}

The Florida Solar Energy Center/University of Central Florida nor any agency thereof, nor any of their employees, makes any warranty, express or implied, or assumes any legal liability or responsibility for the accuracy, completeness, or usefulness of any information, apparatus, product, or process disclosed, or represents that its use would not infringe privately owned rights. Reference herein to any specific commercial product, process, or service by trade name, trademark, manufacturer, or otherwise does not necessarily constitute or imply its endorsement, recommendation, or favoring by the Florida Solar Energy Center/University of Central Florida or any agency thereof. The views and opinions of authors expressed herein do not necessarily state or reflect those of the Florida Solar Energy Center/University of Central Florida or any agency thereof. 
Reprinted from Solar Energy Materials 21 (1990) 191-206.

\title{
Color-rendering of Daylight from Water-filled Light Pipes
}

\author{
Ross McCluney \\ Florida Solar Energy Center \\ 300 State Road 401 \\ Cape Canaveral, FL 32920
}

\begin{abstract}
Water-filled light pipes can be used to transport concentrated beam solar radiation from a solar collection system to a utilization system, altering the spectral distribution of the radiation in a beneficial way in the process. One use for such a system would be for the daylighting of the core interior spaces of buildings, spaces that are far removed from outside walls or the roof and are therefore not amenable to conventional daylighting with sidelights or toplights. The filtering action of the water can be used to remove unwanted infrared and ultraviolet radiation while affecting the visible portion of the radiation only slightly. There are limits, however, to the distance such light can be propagated in water without undesirable color shifts. Comparing with warm white fluorescent light this distance appears to be about 6 to 8 meters. Comparing it to daylight, the distance extends to about 10 to 12 meters. The distance for a significant drop in the color-rendering index is approximately 10 meters. Filters can be added to the light pipe to partially compensate for unwnated color shifts and to extend the maximum distance for transfer, but substantial transmission losses are thereby incurred. Due to these limits, it is suggested that the most likely use of such light pipes would be in a hybrid water/air system, where the water-filled portion of the light pipes would be of limited length and would be used primarily for infrared heat removal. It is possible that separate color-correcting filters can be replaced by appropriately selected dyes added to the water. Another possible use for a version of the water-filled light pipe is for spectral shaping and heat removal in concentrating PV solar energy conversion systems.
\end{abstract}

\section{Introduction}

The daylighting of the interior spaces of buildings provides many benefits [1], including energy savings [2], visual connections with the outdoors (and the psychological benefits deriving therefrom), and good quality, healthy illumination to promote worker productivity [3]. For these benefits to be realized, however, the design of the building must be carefully executed [4] and the problems that can result from improperly placed and shaded fenestration apertures must be dealt with in all stages of the design process [5].

Traditional approaches to daylighting design deal mainly with the perimeter spaces of buildings, leaving the core areas wholly to electric lighting. Several proposals have been made, however, for collecting daylight outside a building and directing or piping it to the interior or core spaces far removed from the perimeter areas [6].

Water-filled light pipes have been proposed for transporting solar direct-beam illumination from concentrating collectors to the cores of habitable spaces [7]. However, water has a nonuniform 
transmittance over the visible portion of the spectrum. Thus, its use as a transport medium will impart a color to the light emerging from the end of the light pipe, as well as an attenuation of the flux passing through the pipe. Countering this is the advantage that by stripping the incident solar radiation of its infrared component, water-filled light pipes can deliver light of high luminous efficacy (ratio of light flux in Lumens to total radiant flux in Watts) to the illuminated space. The heat load on the space cooling system is therby reduced, conserving energy and contributing to enhanced human comfort. The heat removed can even be used for other purposes inside the building, notably for pre-heating domestic hot water.

The purposes of this paper are to describe these effects, provide estimates of the maximum distances solar radiation can be so piped without imparting unacceptable color, and discuss the limits of the use of possible color-correcting filters inserted into the emerging beam.

Problems of attenuation at water-to-air and water-to-solid interfaces, of particulate scattering effects, and the effects of impurities in the water are not addressed. The intent is to determine fundamental limits to the usefulness of the concept, using optimistic but not unreasonable assumptions, not to explore its overall technical feasibility.

\section{Definitions}

Let $c_{\lambda}$ be the extinction coefficient in reciprocal meters of clean water at wavelength $\lambda$ in nanometers. Ignoring multiple scattering effects, if the incident irradiance spectrum is $E_{\lambda}(0)$ in $W$ $\mathrm{m}^{-2} \mathrm{~nm}^{-1}$ then, to a first approximation, the spectrum emerging after propagation through a distance $\mathrm{x}$ in meters will be given by

$$
E_{\lambda}(x)=E_{\lambda}(0) e^{-c_{\lambda} x}
$$

From this expression we can describe the following relevant quantities.

Emerging total irradiance:

$$
E_{e}(x)=\int_{300}^{3000} E_{\lambda}(x) d \lambda
$$

Emerging total illuminance:

$$
E_{\nu}(x)=683 \int_{380}^{760} E_{\lambda}(x) V_{\lambda} d \lambda
$$

where $\mathrm{V}_{\lambda}$ is the C. I. E. standard photopic luminous efficiency function [8]. Spectral transmittance: 


$$
T_{\lambda}(x)=\frac{E_{\lambda}(x)}{E_{\lambda}(0)}=e^{-c_{\lambda} x}
$$

Luminous efficacy:

$$
\varepsilon_{x}=\frac{E_{v}(x)}{E_{e}(x)} \quad[L m / W]
$$

Energy transmittance:

$$
T_{e}=\frac{E_{e}(x)}{E_{e}(0)}
$$

Visible or luminous transmittance:

$$
T_{v}=\frac{E_{v}(x)}{E_{v}(0)}
$$

\section{Effect of Absorption by Water on the Color of Light}

Measurements of $c_{\lambda}$ have been tabulated and plotted by Jerlov [9] and Morel [10]. From these sources, representative values for $c_{\lambda}$ have been obtained in ten-nanometer intervals from 260 to 750 nanometers and in $50 \mathrm{~nm}$ intervals from 750 to $2400 \mathrm{~nm}$. The resulting extinction coefficient spectrum is plotted in Fig. 1.

A Simpson's Rule procedure for integrating over these two different spectral regions was used to calculate the energy and luminous transmittances of light pipes of several lengths. The results are given in Table I. Luminous efficacies of the emerging beams are also included. The corresponding spectral transmittances are shown in Fig. 2.

Plotting the logarithm of the luminous transmittance versus light pipe length in meters yields a line whose slope from 2 to 20 meters is nearly constant at approximately $0.07 \mathrm{~m}^{-1}$. This is shown in Fig. 3. This value can be taken as a very approximate value for the luminous extinction coefficient $c_{v}$ in the expression

\section{Table II. Water-Filled Light Pipe Transmittances and Luminous Efficacy}

\begin{tabular}{llll}
$\begin{array}{l}\text { Distance } \\
\text { in meters }\end{array}$ & $\begin{array}{l}\text { Radiant } \\
\text { Trans- } \\
\text { mittance }\end{array}$ & $\begin{array}{l}\text { Luminous } \\
\text { Trans- } \\
\text { mittance }\end{array}$ & $\begin{array}{l}\text { Luminous } \\
\text { Efficacy } \\
\text { Lumens/W }\end{array}$ \\
\hline 0.001 & .9254 & .9999 & 130 \\
0.01 & .8235 & .9990 & 145 \\
0.1 & .6465 & .9898 & 184 \\
1.0 & .4461 & .9064 & 244 \\
4.0 & .2993 & .7031 & 281 \\
10.0 & .1907 & .4712 & 296 \\
16.0 & .1372 & .3366 & 294 \\
64.0 & .0168 & .0351 & 250
\end{tabular}




$$
E_{v}(x)=E_{v}(0) e^{-c_{v} x}
$$

Evaluation of Eq. 8 for the distances used in Table I shows that this representation can not be used for exacting calculations requiring good accuracy.

Plots of incident and transmitted SPECTRAL TRANSMITTANCE OF PURE WATER solar irradiance spectra are shown in Fig. 4 for pipe lengths of 1, 2, 4, 8 , and 16 meters. It can be seen from this figure that the red portion of the visible spectrum is strongly attenuated for lengths greater than a few meters.

\section{Colorimetry of Water-Filtered Light Pipes}

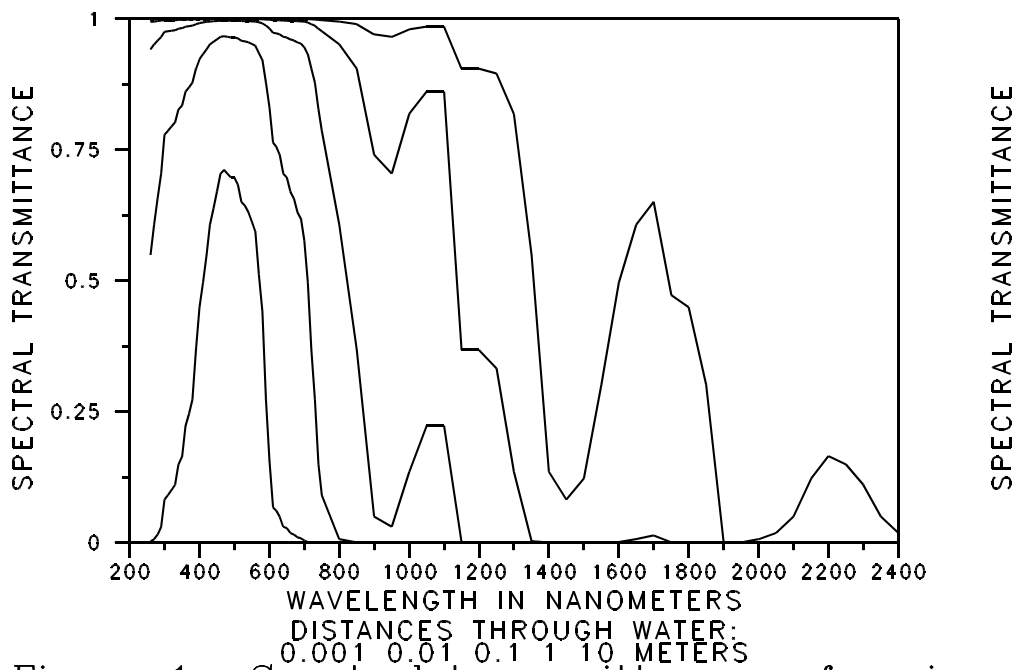

In order to measure this effect

Figure 1. Spectral transmittances of various lengths of water.

quantitatively, the 1931 CIE

spectral tristimulous functions $\mathrm{P}_{\mathrm{x}}(\lambda), \mathrm{P}_{\mathrm{y}}(\lambda)$, and $\mathrm{P}_{\mathrm{z}}(\lambda)$ were used to calculate the chromaticity coordinates $\mathrm{x}$ and $\mathrm{y}$ of spectral irradiances emerging from various lengths of water pipes [11]. The relevant equations are:

$$
\begin{array}{ccc}
X=\int_{370}^{744} P_{x}(\lambda) E_{\lambda}(x) d \lambda & Y=\int_{370}^{744} P_{y}(\lambda) E_{\lambda}(x) d \lambda \\
Z=\int_{370}^{744} P_{z}(\lambda) E_{\lambda}(x) d \lambda & (11) & x=\frac{X}{X+Y+Z} \\
y=\frac{Y}{X+Y+Z} & (13) & z=\frac{Z}{X+Y+Z}
\end{array}
$$

The tristimulous functions are plotted in Fig. 5.

$$
x+y+z=1
$$


Taking the value of 1 for $E_{\lambda}(x)$ at wavelength $\lambda^{\prime}$ and zero for all other wavelengths, calculating the chromaticity coordinates $x^{\prime}, y^{\prime}$ for this "spectrum," and plotting the results for wavelengths $\lambda$ ' from 380 to $750 \mathrm{~nm}$ yields the monochromatic limit curve shown on the chromaticity diagrams to follow.

The chromaticity coordinates can be calculated for radiation emerging from blackbodies at various temperatures in degrees Kelvin. The color coordinates of light sources can be compared to these. One can thereby identify what is called the correlated color temperature of spectra emerging from light pipes in terms of the most closely associated blackbody temperature, according to a defined procedure [12].

According to these procedures, the chromaticity coordinates and correlated color temperatures of spectra emerging from $0,1,2,4$, 10 , and 40 meter water pipes are given in Table II.

This data is plotted on the chromaticity diagram of Fig. 6. For comparison purposes, the coordinates of several commercially available sources of electric illumination are also shown. Using the warm white fluorescent lamp as an indicator of the maximum distance from the white point that is permissible, we see that the corresponding maximum water pipe length would be around 30 meters.

Warm white is perhaps not the best source with which to compare our filtered daylight. Looking at the IES Lighting Handbook 1981 Reference Volume [13], we see that fluorescent sources can

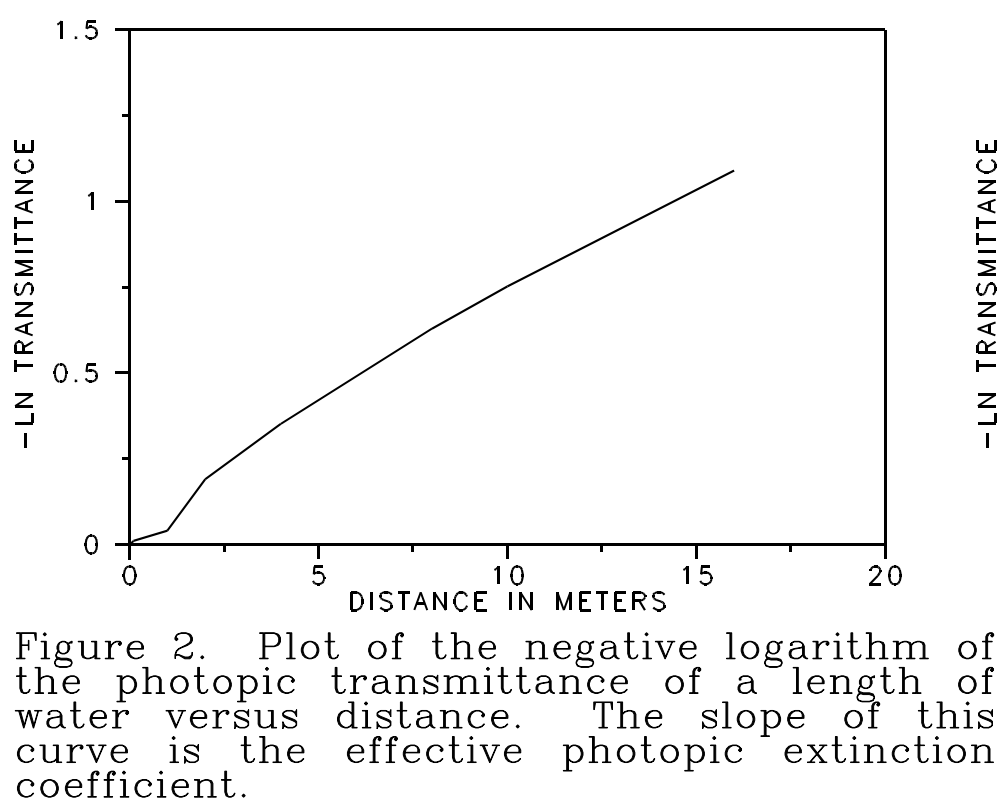
coefficient.

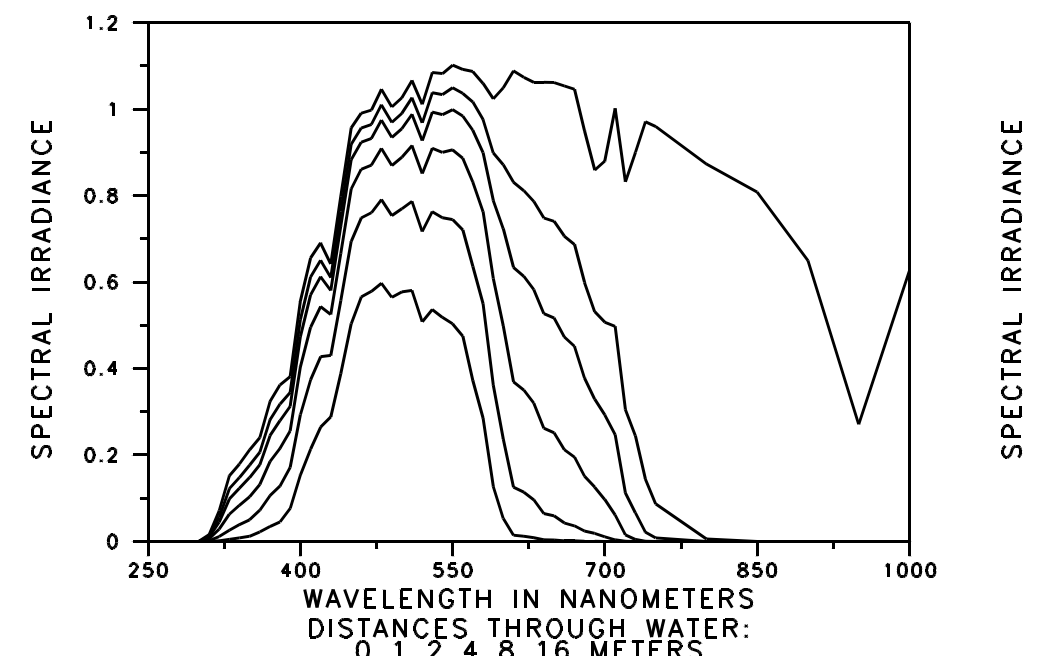

Figure 3. Transmitted irradiance spectrums for various distances through pure water. 
have color temperatures ranging from 5800 to $6500 \mathrm{~K}$. Fig. 5-17 of that handbook, giving the color coordinates of daylight (about $6100 \mathrm{~K}$ and $\mathrm{x}=.31, \mathrm{y}=.33$ ) and several fluorescent lamps, we see that color temperatures over 7000 should not be too objectionable. This would limit maximum pipe lengths for use with fluorescent lamps to about 4 meters. Beyond about 6-8 meters, it is anticipated that the blue/cyan tint of the emerging daylight will start to become quite noticeable when compared

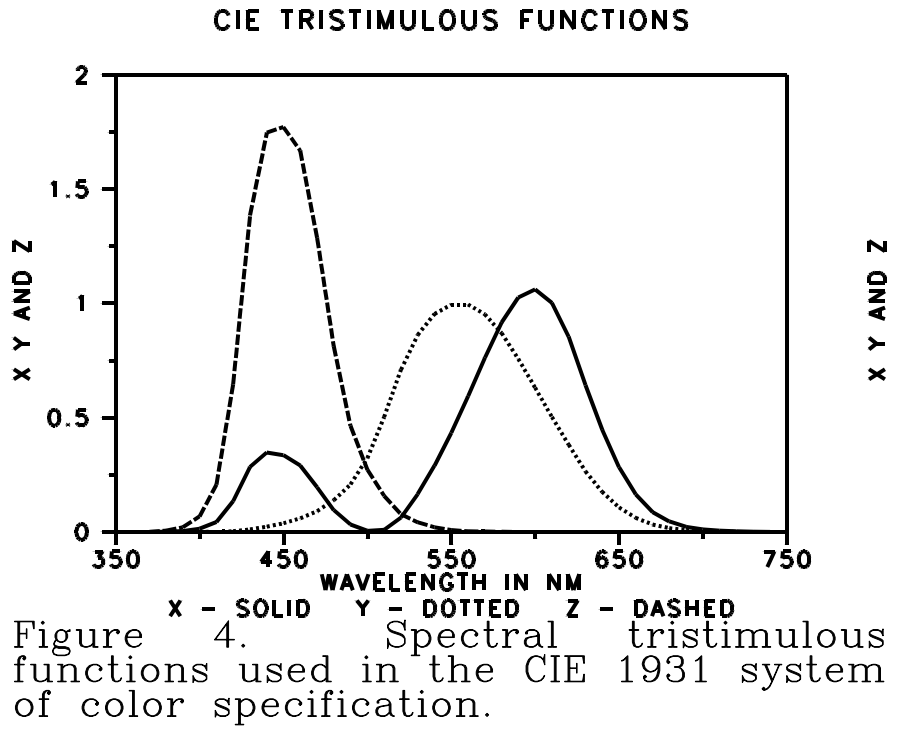
with fluorescent light.

Using this criterion, water-filled light-pipes can just barely be long enough to be useful for illuminating the core spaces of multistory buildings.

This is a little discouraging but can be misleading. Natural daylight has long been accepted as having high color rendering properties. Perhaps it would be better to compare our water-filtered sunlight to some reference daylight spectra. Judd, MacAdam, and Wyszecki [14] subjected 622 Table II. Chromaticity Coordinates and
Correlated Color Temperature daylight spectral irradiance distributions measured by Budde, Henderson, Hodgkiss, Condit, and Grum to eigenvector analysis. They found that the resulting chromaticity coordinates cluster close to the following equation:

$$
y \approx-3.0 x^{2}+2.87 x-0.275
$$


To see how our water-pipe emerging light compares with this daylight color coordinate line, let us plot both on the same graph. The result is shown in Fig. 7. Wyszecki and Stiles [11] state that the correlated color temperature of north clear blue sky light can exceed 40,000 K. According to these authors, overcast sky ranges up to $7000 \mathrm{~K}$, as does diffuse-only horizontal illuminance on a clear day. We can see that the waterfiltered coordinates depart substantially from the daylight ones when the distance exceeds about 10 to 15 meters. The departure from the daylight curve, however, is not as great as the departure from the white point, labelled $\mathrm{W}$ in Fig. 7. Thus, it appears that pipe lengths as great as 10 to 12 meters might be aceptable. A more recent study of the color temperature of light from the sky was completed by Inagaki, Oki, and Nakamura. They found color temperatures ranging from around $5000 \mathrm{~K}$ near the sun on a partly cloudy or hazy day to over $11,000 \mathrm{~K}$ for clear blue sky light about $90^{\circ}$ from the sun [15].
CIE CHROMATICITY COORDINATES

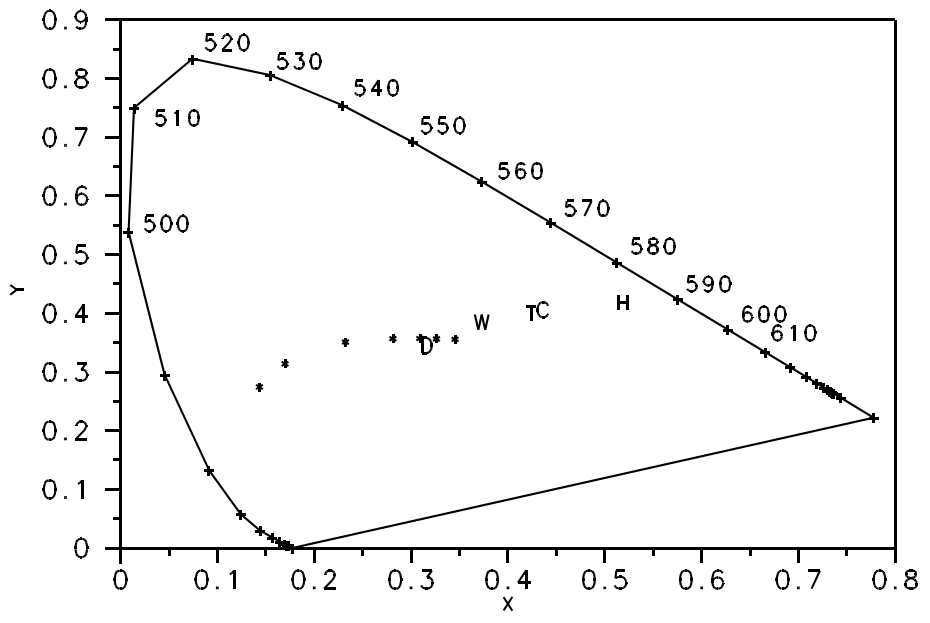

D=DAYL.FL. W=WARMWHITE $\begin{gathered}* \\ \mathrm{C}=\text { COOLWHITE H=HIPRESS. SODIUM }\end{gathered}$ Figure 5. CIE chromaticity diagram showing the colors of daylight, the colors of light emerging from various lengths of water, and the colors of four electric discharge lamps.

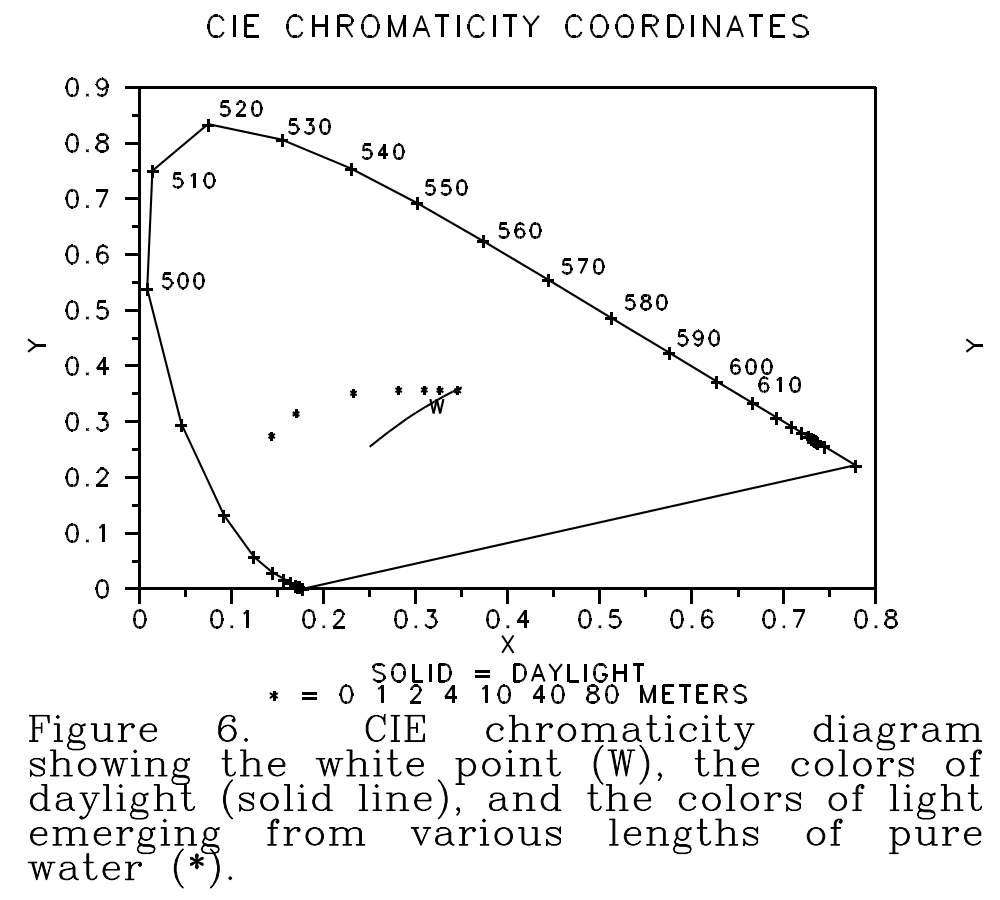

From the literature on evaluating the color of light sources we find that there are two ways of assessing this color. One is personal preference. The other refers to the color rendering properties of the illuminant. The personal preference approach has not been quantified and is so subjective that it is not a suitable basis for selecting illuminants analytically. Ultimately, however, any proposed system of illumination should be evaluated visually by several different observers before final 
decisions are made to use it.

\section{Color Rendering Index}

We will evaluate the color of light emerging from water-filled light pipes using the 1964 CIE Method of Measuing and Speciffing Coldr Randaing Propaties of Iight, Sources [16] This method is based on the definition and use of a Color Rendering Index (CP). The CR is a measure of the shitt in object color that ocours when the object is illuminated by the test source, in comparison to a reference light source, whose CRI is defined to be 100 .

To determine what the reference light source is for a given test source, we must find out what the correlated color temperature of the test source is Once this is known, the reference light source is a Pandian black booly having the same temperature, when this temperature is below $5000 \mathrm{~K}$ Above $5000 \mathrm{~K}$ the reference source is daylight having the same correlated color ter

Kelley [17] and Wyszedi [18] provide a portion of the CE 1931 (x,y) chromaticity diagram with lines of constant correlated color temperature (isotemperature lines) drawn on it, over the range from 0 to 660 micro reciprical degrees (mireds). Corrdated color temperature $\mathrm{T}_{\mathrm{c}}$ is related to mireds by. $\mathrm{T}_{\mathrm{c}}=10 \% / \mathrm{mired}$. The diagram is abo published in the $\mathbb{E S}$ lighting Itandbook [13] and temperatures are given in reciprocal megakekins, a unit that has replaced the microreciprocal degree. This graph can be used to detemine $\mathrm{T}_{\mathrm{c}}$ for any light source of known chromaticily coordinates that fall in the range of the plot. This is the method used here to determine correlated color temperatures.

To calculate the CPI we must transform the $1931 \mathrm{CE}$ coordinates (xy) into the coordinates (u,v) of the CIE 1964 Uniform Colour Space:

$$
u=\frac{4 x}{-2 x+12 y+3}
$$

$$
v=\frac{6 y}{-2 x+12 y+3}
$$

We also need the parameters $c$ and d, defined as

$$
c=\frac{1}{v}(4-u-10 v) \quad d=\frac{1}{v}(1.708 v+0.404-1.481 u)
$$

These, and additional parameters, are calutated for both the test and the reference illuminant, as well as for the product $\beta$

reference color samples This data is then used to calculate the degree of colorimetric shilt of the light reflected from eight reference objects exposed to the test illuminant, compared with their color when exposed to the reference illuminant. The CR is the mean of the differences $\mathrm{R}_{\mathrm{r}}$ 
$\Delta K$

reference color sample.

A computer program was written to perform these calculations, following the procedure described by Nickerson and Jerome [19]. The reference illuminant spectral distribution was cakulated from the black body radiation law:

$$
M_{\lambda}=\frac{c_{1}}{\lambda^{5}\left(\frac{e^{c_{2}}}{\lambda T}-1\right)} \quad\left[\frac{W}{m^{-3}}\right]
$$

where

$$
c_{1}=3.741 \times 10^{-16} \quad\left[\mathrm{~W} \mathrm{~m}^{2}\right]
$$

and

$$
c_{2}=1.439 \times 10^{-2} \quad[\mathrm{~m} \mathrm{~K}]
$$

The results are shown in Table II, Table III. Color Rendering Indices

along with the color temperature and color rendering index from the $\mathbb{E S}$ Lighting Handbook [13] for several dectric light sources for comparison. The CRI values are plotted versus distance of travel in

I we take a CH of 50 as a minimum, it appears that the maximum permitted ditance is about 10 meters or $33 \mathrm{ft}$. This is a very respectable value. The quantity of light emerging CORRELATED SOURCE $\quad$ COLOR TEMP Warm $\underline{\text { WRI }}$ white fluor. $\quad 3020$ Warm white deluxe 2940 Cool white fluor. $\quad 4250$ Cool white deluxe 4050 Daylioh中ifluor. 6250 Metal hafide lamp 3720 High pressure Xenon 5920 High pressure sodiento Tungsten Halogen 3190 Sun + water, 2 motes 82 Sun + water, 4 mêté̃s 70 Sun + water, 10 meteo\$989 Sun + water, 40 met38,333 is not great at such large distances, as is seen in Table I, but useful quantities could be provided. A possible fallacy with this approech comes from the definition of color rendering index by reference to another light source, itself chosen to be a good one, at least for rendering colors. By shifting the reference paint for assessing the CPI of dayight emerging from different lengths of water, we are refening back to light which itself is gelling bluer and bluer- deeper blue sky light, essentially. The light pipe makes this light even bluer, and can impart a bluish tint to some o 
The eye is quite adaptable to color shitts and can still distinguish different colors even in the presence of these shitts This hes been amply demonstrated with modem high pressure soclum vapor bmps which impart a yelbwith tint, but are sill capable of providing tolerable color rendering, even though the CRI value shown in Table $\mathbb{I I}$ is low. However, light which is considerably bluer than the bluest dayight can be expected to have some resitance to its use for ambient and/or tadk illumination by building ocapants Thus we mut temper the

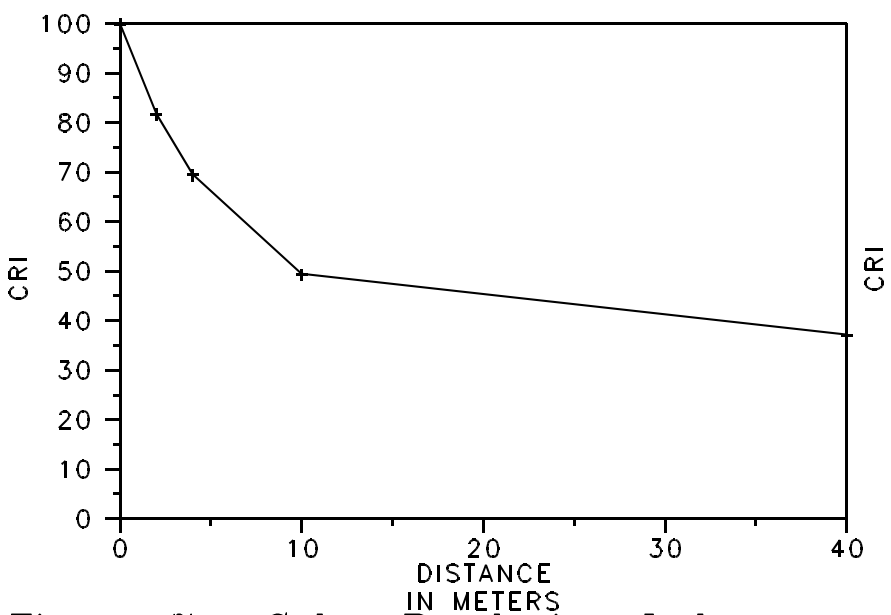

Figure 7. Color Rendering. Index as a function of distance sunlight travels through pure water. optimitic results gien above with the caution that color-rendering index alone is not a sufficient measure of the acceptability of a light source.

\section{Color-Correcting Filters}

It might be possible to correct the blue appearance of water-filtered light by the use of color correcting filters to improve the color-rendering of the light. This will inevitably result in loss of light flux, since the fitter will, in essence, be stripping off some of the blue partion of the spectrum to better match the red portion. At great distances the red is almost completdy gone and no amount of fitering will be able to bring it back. This method will therefore be of limited usefulness

Iooking at a Kockak fitter catalog, filter series 86 (yellowish) appears to have spectral transmiltance curves that would be capable of attenuating the blue end of the color spectrum much more than the red end. Four filter transmittances were selected, for fiters $86,86 \mathrm{~A}, 86 \mathrm{~B}$, and $86 \mathrm{C}$. The spectral transmiltance of each of these was multiplied by the spectrum of light emerging from 10 meters of water and the chromaticity coordinates of the resulting fittered spectra were calculated. These are plotted in Fig. 9 . Iooking at the four arres that come together at one point on this plot, the point where they come together is the unfiltered 10 meter point. The four additionally fittered points are indicated by the numbers 1 through 4, indicating the effect of these four filters on the light emerging from the light pipe The lines are drawn to indicate the effects of each of the four fitters in moving the color of the light emerging from the light pipe upward and to the right. The white paint is labeded W on this figure and daylight colors are indicated by the lower solid line.

We can sce that these filters do tend to move the coldr of the light emerging from the pipe more toward 
the night and away from the blue region of the spectrum, but the resulling color is above the white paint, in the direction of greenish yellow. This may be an acceptable color but it is difficult to tell without calculating the the CRI values and obtaining visual appraisals of the

CIE CHROMATICITY COORDINATES

Let us see if a more optimum filter transmiltance spectrum can be defined There are several passible definitions of such a spectrum. One would be to invert the effect of the water, that is, to have a filter transmitance spectum that is the complement of the water transmiltance $\mathrm{Eq} 4$ gives the spectral transmiltance of the water at ditance $\mathrm{x}$. The color correcting fitter proposed here would have its transmittance

$$
T_{f \lambda}=1-e^{-c_{\lambda} x}
$$

Mulliplying the 10-meter transmilted spectral

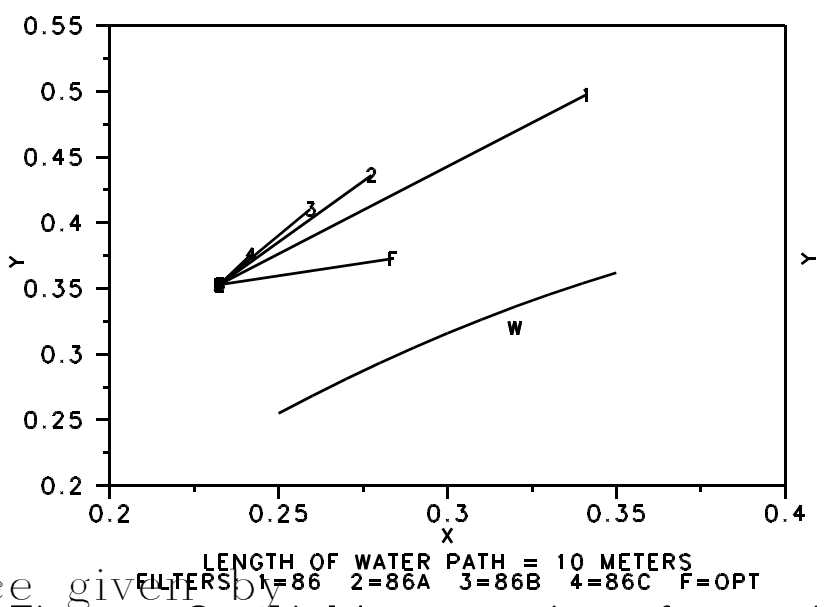

Figure 8. Light emerging from 10meters of water and from several Kodak filters. W indicates the white point and the lower solid line is the daylight color line described in Eq. 16. $\mathrm{F}$ is for a theoretically optimum filter. flux arve by this spectral transmiltance and calaulating the resulling chromaticity coordinates yidds point F in Fig. 9. This point is doser to the dayjight line and the white point than the points for the Kodak filters.

Another possibility would be to dissolve suitably chosen dyes in the water to further atter its spectral transmiltance. This method was used by Laporta and Zaraga [20] to make transmilting bandpess filters for the ultraviolet portion of the spectrum and followed more genera

It seems from these results that further work in developing optimum fitters could yidd even greater improvement in the color-rendering properties of water-filtered sunfight. Through this method, it should be possible to extend the acceptable distance which light is permilted to travd through a water-filled pipe to, say, 10 to 15 metess There will, however, be substantial loss of flux through the water and the colorcorrecting filter, with an overall transmittance to visible light below 
Plots of the spectral responses of two photovoltaic energy conversion cells [22] are shown in Fig. 10, along with plots of the spectral transmittances of water for 1, 4, and 16 centimeter path kngths One can see from this that the water effectidy serves as a lowpass filter of the radiation incident on the cells, culting off radiation with wavelengths greater than those in the transition region shown in the Figure. The location of the atoff region can be adjisted by changing the path length through the water. Clearly longer

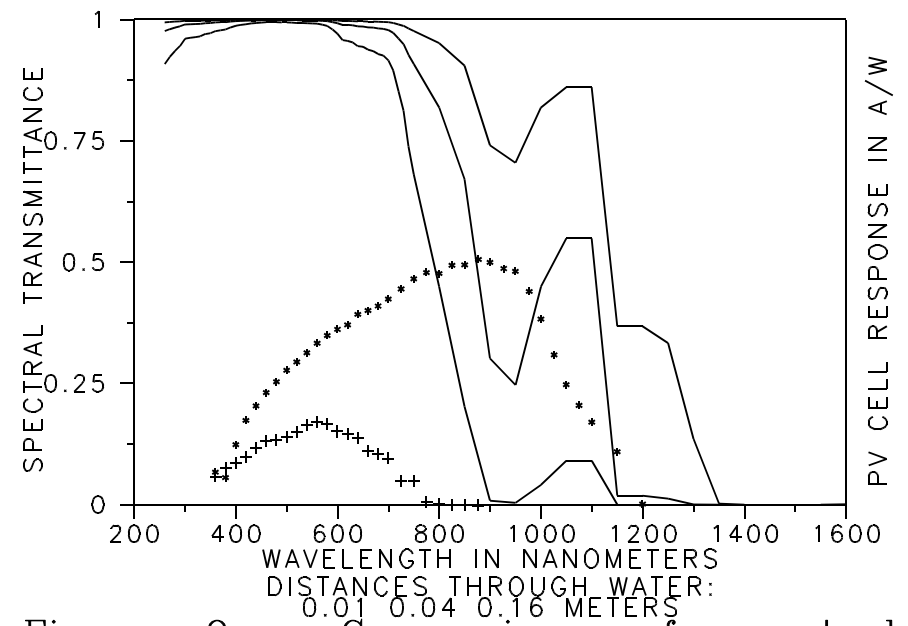

Figure 9. Comparison of spectral responses of two photovoltaic cells with the spectral transmittance of water. $+\quad$ Amorphous silicon Monocrystaline silicon. path lengths are appropriate for cells with a limited range of spectral response, such as the amorphous silicon ones Shorter path lengths appear better suited for cells with extended spectral response, induding monocrystalline and polycrystalline ones.

\section{Conclusions and Recommendations}

Water -filled light pipes can be used to bring cool, fittered sunlight indoors in a controlled manner. As this light travels through such pipes, spectrally selective absonption and scattering in the water removes infrared radiation and reduces the flux of red light more than other parts of the visible spectrum. The result is light of sightly bureish color which has reduced color-rendering properties The distance which this light can be tranemitted before its color becomes dbjectionable in comparison with warm white fluorescent light appears from this preiminary assessment to be about 6 to 8 meters Comparing it to daylight, the distance extends to about 10 to 12 meters The distance for a significant drop in its color rendering index is approximately 10 meters Color-correding fitters can be designed for use with such pipes to extend the maximum distance of light tranfer but the attenuation of light resulling from these combinations greatly reduces the efficiency of the pipe.

The visibe transmiltance of 5 and 10 meter long pipes is about $20 \%$ and 19\%, respectinely. Use of colorcorreding filters will drop this even further. For some applications, mainly those which can tolerate relatively low levels of illumination, or applications where cost-effectiveness is not a major consideration, these light losses might be tolerable since they can be compensated for by using barger sunlight collection systems In other cases, the white appearance of the emerging light, its color-rendering property, and the efficiency of transmission are very important In such cases only short lengths of water-filled pipes can 
be used.

It seems that the best solution in such cases would be a hybrid combination of air-filled and water-filled light pipes The water-filled section would strip off the infrared portion of the spectrum, recucing the themal energy content of the emerging beam, and the air-filled portion would distribute the light to the areas needing illumination. The higher refractive index of water could serve an optical purpose in the design of the concentrating collector used to fous sunlight on the pipe. The water could fill the collector (if the structural loading resulting from the weight of the water can be handled acceptably) thereby increasing the concentration ratio. The water-filled portion could be placed at the focus of the concentrator, and shaped to improve flux throughput. Ather hybrid possibilities can be explored for special application areas.

The possibilities for use of water to fitter the radiation impinging upon solar photovoltaic energy conversion arrays are intriguing and should be explored further. Not only can the water remove unused infrared radiation from the illuminating beam but ako it can be employed as a cooling medium, lowering the operating temperatures of the array and hence increasing conversion

\section{Acknowledgement}

Pations of this work were supported by the Assitant Secretary for Conservation and Renewable Fnergy, Office of Buildings and Community Systems, Building Systems Division of the US. Department of Fnergy through grant DE-FG01-84CE22122.

\section{References}

[1] Selkowitz, S. E and R Johnson, "The Daylighting Solution," Solar Age, Vol. 5, No. 8, August 1980, Pp $14-20$.

[2] Griffith, J. W, 'Daytight and Fnergy Conscious Desion?" ASHRAE Transadions DF-29-5, No. 4, 1999 pp. 664-668. Treado, S., G. Gillette, and T. Kusuda, "Evaluation of the Daylighting and Energy Performance of Windows, Skytights, and Clerestories", National institute for Standards and Technology (formerly NBS), Pub. NBSIR 83-2726, June 1983.

[3] Benton, C. C, 'Daytighting Can Improve the Quality of Light and Save Fnergy," Architectural liphing, Vd. 1, Nov. 1986, pp. 46-48. Oddo, S, "Surprising Discoveries About Why You Need More Natural iight, House and Garden, Vol. 148, Feb. 1976, pp. 78 -79. Gillette, G, "The Case for Daytighting," The Construction Specifier, March 1984, pp. 58-63.

[4] McCluney, R., "Bringing in the Sun," Glass Magazine, August 1986,

[5] Selkowilz, S. F, 'What Makes Dayighting Fffective?' Fnergy Management, June/July, 198, pp. 32 31,11. Moluney, R 'Daytighting in America - Some Practical Suggestions for Proper Lsage" lighting 
Desion \& Application, July 1985, pp. 36 - 38. Shanus, M. D., et. al, "Going Beyond the Perimeter with Daylight, Lighting Design \& Application, March 1984, p. 30-40.

[6] Fraas, L M., W. R. Pyle, and P. R. Ryason, "Concentrated and Piped Sunlight for Indoor Illumination," Applied Optics. Vol. 22, No. 4, 15 Feb, 1983, p. 578-582. Duguay, M. A, "Solar Flectricity. The Hybrid System Approach," American Scientist, Vol. 65, July/August, 19r\%,.pp. $422-427$. Duguay, M. A and R M. Adgar, 'legting with Sunlight Ling Sun Tracking Concentrators, Applied Optics, Vol 16, No. 5, May 197\%, pp. 1414-1446. Iilthefair, P., 'Beam Iighting: A Pipe Dream?", Hectrical Desion, May 1986, pp. $31-33$.

[7] Kank, B. and Cerod, D, 'Daylighting with Fibre Optics' Iike Water Tubes," Proc, gin Passive Solar Conference, Columbus, Ohio, American Solar Fnergy Society, 2400 Central Ave, Suite B-1, Boulder, CO 80301, Sept. 1984.

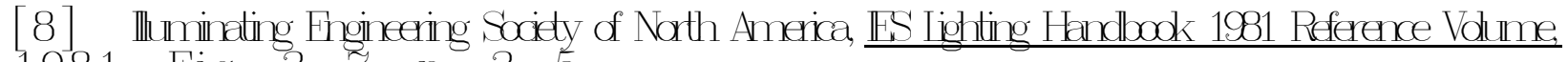
1981, Fig. 3-7, p. 3-5.

[9] Jerlov, N. G., Marine Optics, Elsevier, New York, 1976.

[10] Morel, A, "Chapter 1. Optical Properties of Pure Water and Pure Sea Water," Optical Aspects of Oceanography, N. G. Jerlov and E. S. Nielsen, eds., Academic Press,

[11] Wyszecki, G., and W. S. Stiles, Color Science: Concepts and Methods. Quantitative Data and Formulas, Wiley, 1967.

[12] Kelley, K L, 'Iines of Constant Corrdated Codor Temperature Based on MacAdamis (uv) Uniform Chromaticity Transformation of the CIE Diagram," J. Opt. Soc. Am, 53,999 (1963). Driscoll, W. G, and Vaughan, W., Handbook of Optics McGraw-Mill, New York, 19r8. Robertson, A R, "Computation of, Correlated Color Temperature and Distribution Temperature,"

[13] Mluminating Fngineering Socidy of North America, $\mathbb{E S}$ Lighling Itandbook Reference Vdume, 1984, p. $5-14$.

[14] Judd, D. B., D. L. MacAdam, and G. Wyszecki, J. Opt. Soc. Am. 54,

[15] Inagaki, T, Oki, M, and Nakamura, H, "Study on Cobur Temperature of Iight From Sky and its Distribution in Japan," Proceedings of the $6^{\text {th }}$ Session of the Association Internationale de la Colour, Buenos Aires, Argentina, 1989, Vol. II - Papers.

[16] CF, Method of Measuning and Specifying Colour Rendering Properties of Jight Sources, $\mathrm{CE}$ Publication no. 13.2 (TC 3.2), 1974.

[17] Kelley, K. L., J. Opt. Soc. Am. 53, 999 (1963).

[18] Wyszedki, G., 'Section 9. Colorimetry", Handbook of Optics, W. G. Driscoll and W. Vaughan, edk, McGraw-Hill, New York, 19xx.

[19] Nickerson, D. and C. W. Jerome, "Color Rendering of Light Sources CE Method of Specification and Its Application," Illuminating Engineering, Vol. 60, No. 4, April 196

[20] Laporta, P. and Zaraga, F., "Computer Design of Liquid Fitters Made of Aqueous Solutions of Transition Metal Ions," Applied Optics 20,2946 (1981).

[21] Ingersoll, K. A., Applied Optics, 10, 2781 (1971); 11, 2473 (1972); 
[22] Fmery, K A, et al "StR Results from the PFP 1987 Summit Round Robin and a Comparison of Photoroltaic Calibration Methods", Solar Fnergy Research Institute, 1617 Cole Btyd, Golden CO 80401, Report: SERI/TR-213-3472, March 1989, p.28. 